\title{
Alexandre Papadiamantis : Aspects poétiques du monachisme dans l'œuvre du Saint des Lettres Grecques
}

Alexander Papadiamantis: Some Aspects of Monasticism in the Work of the Modern Greece's National Writer

\section{Nicolas Evzonas}

\section{CpenEdition}

Édition électronique

URL : https://journals.openedition.org/ceb/5021

DOI : 10.4000/ceb.5021

ISSN : 2261-4184

Éditeur

INALCO

\section{Référence électronique}

Nicolas Evzonas, « Alexandre Papadiamantis : Aspects poétiques du monachisme dans l'œuvre du Saint des Lettres Grecques », Cahiers balkaniques [En ligne], 42 | 2014, mis en ligne le 02 juin 2014, consulté le 07 juillet 2021. URL : http://journals.openedition.org/ceb/5021 ; DOI : https://doi.org/ $10.4000 /$ ceb.5021

Ce document a été généré automatiquement le 7 juillet 2021.

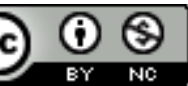

Cahiers balkaniques est mis à disposition selon les termes de la Licence Creative Commons Attribution - Pas d'Utilisation Commerciale 4.0 International. 


\section{Alexandre Papadiamantis : Aspects poétiques du monachisme dans l'œuvre du Saint des Lettres Grecques}

Alexander Papadiamantis: Some Aspects of Monasticism in the Work of the Modern Greece's National Writer

Nicolas Evzonas

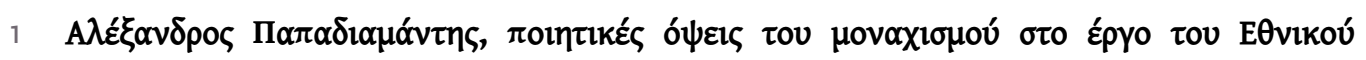

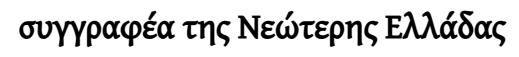

\section{Introduction}

2 Alexandre Papadiamantis (1851-1911), auteur emblématique de la prose néohellénique qui jouit en Grèce d'un statut équivalent à celui d'un Balzac ou d'un Flaubert en France, est littéralement assimilé à une icône dans son pays natal comme en témoignent ses portraits d'inspiration ouvertement religieuse. Conséquence naturelle de cette " hagiographisation » et de sa réputation, toujours d'actualité, de "Saint des Lettres grecques »- due à son existence pieuse et austère, à ses textes truffés de références aux rites orthodoxes et de renvois bibliques et ecclésiastiques, le tout mélangé à une haute dose d'idéologie et d'hellénocentrisme militant-, c'est l'approche théologique et téléologique de son univers artistique qui a longtemps prévalu. Si bien que son imaginaire proprement littéraire demeure encore largement une terra incognita.

Le présent article, qui s'inscrit dans une démarche de recherche généraliste et résolument interdisciplinaire visant à combler cette lacune ${ }^{1}$, se propose d'apporter quelques éclairages sur l'aspect poétique du monachisme et de la foi religieuse dans l'œuvre de Papadiamantis, qu'il convient de distinguer, afin d'éviter tout malentendu, de la piété que l'auteur a pu manifester dans sa vie extralittéraire. Notre étude se veut par ailleurs une plongée dans l'univers fascinant de cet écrivain peu connu en France 
pourtant digne de figurer au panthéon de la littérature mondiale aux côtés de Proust, de Poe ou de Dostoïevski.

4 Notre contribution se centrera sur les Marchands des Nations [oi " $E \mu \pi \circ o$ ol $\tau \tilde{\omega} v$ ' $E \theta v \tilde{\omega} v$; 1882], le deuxième roman publié de Papadiamantis et chronologiquement le premier texte qui nous introduit dans le milieu intrigant des moines et des moniales. Les informations très riches sur la vie claustrale tournent essentiellement autour de l'expérience de l'héroïne principale du récit, Augusta - digne de figurer parmi les plus grandes figures amoureuses de la littérature européenne aux côtés de la Didon de Virgile ou de la Phèdre de Racine -, éperdument éprise de l'homme qui l'a ravie à son époux, qui se réfugie à deux reprises dans des monastères. On retrouve également une série de personnages secondaires qui gravitent autour d'elle qui nourrit par leurs actes et/ou leurs paroles l'« anatomie » de ce monde particulier.

\section{La réclusion claustrale comme remède à la frustration amoureuse}

5 Augusta est l'épouse dévouée et vraisemblablement heureuse d'un aristocrate de l'île de Naxos, au XIII ${ }^{\mathrm{e}}$ siècle, jusqu'à ce que le comte vénitien Marcos Sanudo, introduit dans la maison en tant qu'ami et allié de son mari Mouchras, l'arrache à son foyer et l'oblige à devenir sa maîtresse. Lorsque le narrateur la fait reparaître au milieu du roman sous un habit de religieuse et un autre nom, désireux de ne pas révéler immédiatement l'identité de ce « nouveau » personnage, il laisse planer la question suivante :

Existe-t-il des femmes qui se réfugient dans les monastères par écœurement et d'autres qui embrassent la vie monacale pour combler une faim profonde? Sans doute. Et à quelle catégorie cette femme-là appartenait-elle ${ }^{2}$ ?

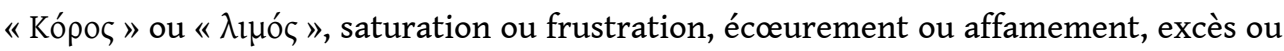
manque, un surplus de plaisir ou un défaut de plaisir peuvent-ils pousser un être à endosser l'habit monastique? Les deux volets de la question suggèrent en tout cas la présence d'une souffrance et d'un sentiment de malaise; on entre au monastère, semble-t-il, pour soigner un mal-être (un mal d'être ?). La réponse précise à la question du narrateur ne tarde pas à apparaitre dans le texte puisque la jeune femme, alitée et à l'évidence tourmentée, avoue à son confesseur avec une stupéfiante sincérité qu'elle s'est retirée au couvent non pas pour communiquer avec Dieu, mais pour panser les plaies de son cœur, occasionnées par l'infidélité et l'inconstance de son amant adultère :

Si j'ai quitté le comte, je l'ai fait par dépit amoureux et folle jalousie, non par volonté de sauver mon âme ${ }^{3}$.

La suite du discours de l'héroïne révèle la nature et l'essence de cette jalousie :

Tel un condamné ligoté au poteau par lequel sa peine doit s'accomplir, mon âme est attachée à cet amour qui est mon châtiment pour le siècle présent et les siècles à venir. J'aime celui qui a détruit mon bonheur conjugal et lacéré le cœur de mon époux, je l'aime avec une telle ardeur et une telle fureur que j'en viens à ressentir cet Éros comme un démon habitant ma chair ou plutôt une légion entière de démons se répandant dans mes veines, pareille à une pieuvre déployant ses tentacules, me suçant le sang et m'étouffant ${ }^{4}$.

8 Donc, la motivation à l'origine du choix de la réclusion monastique est la frustration amoureuse; c'est le « $\lambda_{\imath \mu o ́} \varsigma$ " [faim, manque] à cause d'un amour inadéquatement 
comblé, d'un besoin concupiscent, atrocement charnel, physique et nullement métaphysique, d'une passion carnassière insatiable et irrémédiable, d'un Éros narcissique et possessif qui ne tolère pas de partage. Il s'agit aussi d'expier le «crime » que constitue une pulsion si exubérante qu'elle défie toute logique, avilit et rend esclave, qu'elle fait préférer l'amant-bourreau à l'époux bienveillant. Le narrateur, qui reprendra en résumé l'histoire d'Augusta vers la fin du roman, soulignera que son héroïne a embrassé la vie monacale dans l'espoir de se libérer d'un double joug tyrannique : les affres de la jalousie et le désillusionnement amoureux d'une part, et le remords d'un égarement qui lui barre toute possibilité de retour au foyer conjugal d'autre part.

Mais elle ne tarda pas à comprendre que son amour ne suffirait jamais à combler ce cœur égaré et indiscipliné ; elle comprit que Sanudo était infidèle, incapable d'aimer véritablement et qu'il papillonnait en tous sens. Il était donc impossible pour Augusta de rester avec lui et tout aussi impossible de retourner auprès de son époux. Où trouverait-elle refuge? Toutes les portes lui étaient fermées. Il existait heureusement en ce temps-là un havre spacieux, un nid immense, capable d'offrir à tous un abri en son sein: le monastère. Elle s'y rendit dans l'espoir d'oublier le monde et de trouver le bonheur dans la solitude ${ }^{5}$.

9 Nous discernons le désir de défaire les liens avec les autres et de renouer avec soimême, sous-tendu par le souhait de se réfugier dans un giron accueillant pourvoyeur de quiétude bienheureuse, alias le rêve de retourner dans le ventre maternel - même si

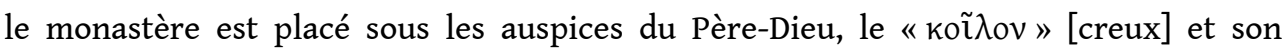
extrapolation inéluctable " koi $\lambda i ́ \alpha$ » [ventre] renvoient immanquablement au corps de la mère. Rien d'extraordinaire ici: lorsque la rencontre avec l'«autre" s'avère traumatisante, le fantasme de régression vers un narcissisme préobjectal quiétal est « de mise ».

10 On insistera sur l'absence de mobile religieux et sur l'idée de contrainte associée à l'engagement dans la vie conventuelle. Les paroles que Kaekilia - la malicieuse Vénitienne missionnée par Sanudo pour rechercher Augusta et la ramener auprès de lui - adresse à la jeune religieuse «inconnue » dans le dessein de la piéger et de la pousser à dévoiler son identité sont très significatives à cet égard :

Imaginez une jeune fille ou une jeune femme, brune ou blonde, friande de mondanités et de futilités, en proie à une folle passion, contrainte de revêtir l'habit monastique que Dieu dans son infinie mansuétude lui accorde le droit de porter. [...] Jeune, tendre, ravissante, pleine d'attraits, incarnation de la joie, de la fraîcheur et de l'espoir, et tombée dans le piège de l'amour ! [...] Victime de l'amour ! Et obligée de devenir religieuse! Combien sont-elles dans ce cas! Et quels tourments ineffables, quelles ardeurs, quels désirs et quels martyres doivent se dissimuler sous leur voile! Seul le diable connaît ce que l'âme d'une jeune fille ou d'une femme recèle... surtout celle d'une femme. Une jeune fille peut commettre l'erreur de devenir nonne par légèreté ! Mais une femme ? Une femme mariée ? Qui sait quelle passion irrépressible l'a dévoyée et quelle cruelle nécessité l'a conduite au couvent ${ }^{6}$ ?

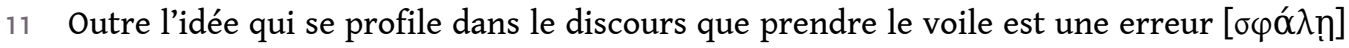

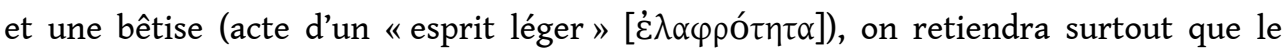
couvent est esquissé comme une confrérie ou, pour être plus précis, une « consœurie » de victimes de l'Éros [ $\theta \tilde{u} \mu \alpha$ ع̌ $\rho \omega \tau o \zeta]$, une congrégation de femmes égarées et dévoyées

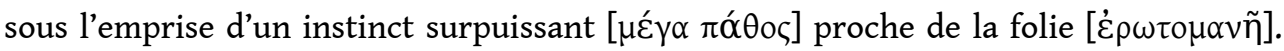
On soulignera aussi que la seule implication de Dieu dans cette initiative aux allures

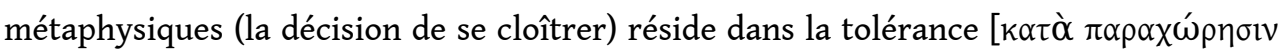


$\Theta \varepsilon o \tilde{]}]$ que Sa magnanimité manifeste vis-à-vis de ces pauvres créatures poussées par la

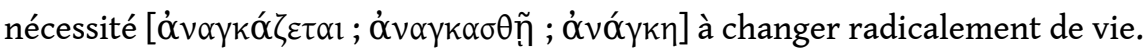

\section{La suprématie de l'Éros égocentrique sur l'Agapè théocentrique}

12 Il est évident qu'une telle démarche effectuée à contrecœur et dénuée de toute authenticité sera vouée à l'échec. L'exemple d'Augusta le prouve triomphalement. L'héroïne est cruellement déçue dans son double espoir de soigner la pathologie de son Éros et d'apaiser la culpabilité induite par celle-ci en s'enfermant dans un monastère. Le narrateur le dit sans ambages:

Cet espoir était illusoire. La malheureuse Augusta était désormais destinée à être hantée par deux souvenirs opposés : le premier la menaçait, l'autre la torturait; le premier la tyrannisait, le second la poursuivait. Elle lutta, résista, souffrit mille tourments et mille martyres. En vain. Elle épuisa toutes les voies. [...] L'asile promis par la religion s'avéra insuffisant ${ }^{7}$.

On s'étonnera de constater à quel point ce refuge s'avère illusoire et imparfait. Le discours d'Augusta à son confesseur dévoile la force inouïe de son désir charnel pour Sanudo et constitue une ode stupéfiante à l'omnipotence de l'Éros - véritable « hapax " dans le corpus papadiamantien $-^{8}$, à côté de laquelle la puissance du Dieu chrétien paraît bien pâle et fragile. Ce qui impressionne surtout, c'est la faiblesse proclamée de l'esprit face au pouvoir impérialiste de la chair et l'impuissance de la conscience devant le débordement de la pulsion à laquelle on prête une origine démoniaque. Lorsque l'héroïne exprime hardiment son absence de repentir, elle ne fait en réalité que révéler l'impossibilité de contrôler les rejaillissements de son Éros et souligner le règne absolu de ce "suppôt de Satan" qui supplante tout sentiment, s'élève au-dessus de toute appétence morale et balaye toute foi religieuse.

J'admets qu'il vient parfois un moment où l'âme se recueille et pleure tout bas ou adresse de véhémentes lamentations au Tout-Puissant, pensée suprême de tout esprit. Cependant, cet instant s'enfuit, comme tous les instants s'enfuient, et la chair reprend ses droits et réclame son dû̀ .

Je ne me suis jamais repentie de ce crime, mon Père, et je ne crois pas qu'il me soit possible de le faire. Comment, mon Père, Dieu permet-il l'existence, dans la nature qu'il a créée, d'un sentiment plus puissant que la foi en Lui et d'une loi supérieure à Sa toute-puissance? En vain, mon Père, je prolonge les jeûnes, en vain je me prosterne mille fois chaque jour. La chair est rétive à tout apaisement, l'Éros rebelle à toute capitulation. Alors même que mes lèvres murmurent machinalement les prières conventionnelles apprises dans mon enfance, son nom retentit sans cesse dans mon cœur...10

Je ne crois pas que le véritable repentir existe, mon Père, sauf si l'on nomme ainsi la simulation du repentir et l'hypocrisie ${ }^{11}$.

Dans ce contexte, le nom adopté par Augusta lorsqu'elle se fait moniale, censé correspondre à sa nouvelle quête et à sa nouvelle identité, acquiert une savoureuse ironie : la femme enflammée, consumée par la passion, détournée de l'amour pour ses proches ainsi que de l'amour pour Dieu $^{12}$, la ravissante religieuse dont le corps dissimule mal sa splendeur sous la tenue monacale ${ }^{13}$, la pénitente tourmentée qui réitère le vocable « $\varepsilon \omega \varsigma \varsigma$ " pour parler des manifestations de son désir luxurieux a choisi de s'appeler «A Aүó $\pi \eta$ » [Agapé] ! Quoi de plus renversant que de constater que ce prénom, qui fait clairement référence à l'amour chrétien théocentrique ${ }^{14}$ et que le texte associe 
aux vœux monacaux de chasteté prononcés par l'héroïne, est annulé, voire annihilé,

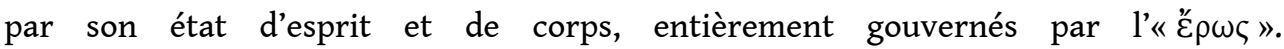
Linguistiquement ce dernier renvoie à l'amour antique, notamment platonicien et plotinien, dans lequel convoitise et désir inhérents au manque ne sont nullement

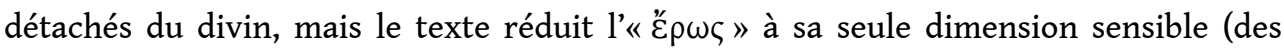
sens) et égocentrique comme pour mieux le diaboliser... Le message est clair : l'Éros compris comme pulsion sexuelle indissociable de la jalousie et de la possessivité est infiniment plus puissant que l'Agapè perçue comme consécration à Dieu et comme ascétisme moral et corporel.

On se rappellera ici la nonne catholique du long récit de Papadiamantis les Rivages roses

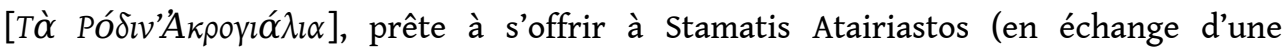
conversion de celui-ci au catholicisme), lequel ironise sur ce dévouement de « Sœur de

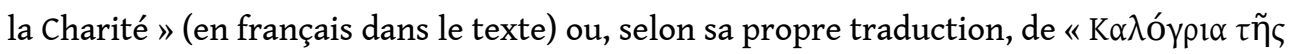
Aүớđin » [Moniale de l'Agapè] ${ }^{15}$ : une femme vouée à la chasteté et à l'amour spontané et désintéressé qui propose un " amour » sexuel, calculé et intéressé !

Il est indéniable qu'une telle utilisation du nom "Agapè » constitue une moquerie. Augusta-Agapè, dévorée par l'Éros sous son voile de religieuse et sous le fichu noir qui peine à masquer son envoûtante crinière dorée, met superbement en exergue la vanité $\mathrm{du}$ " déguisement » monacal et son caractère dérisoire ${ }^{16}$. Ce n'est certainement pas une surprise si, par ailleurs, l'héroïne finit par quitter le monastère pour aller rejoindre Sanudo, la seule déité qu'elle sait vénérer, et cela à deux reprises, une fois à Patmos et une autre à Naxos. C'est l'ultime rappel de la suprématie incontestable du Dieu-Éros face au Dieu agapique.

\section{Le désert étouffant de l'Éternité}

Ce n'est pas seulement l'incapacité de l'héroöne à trouver une consolation dans la religion qui doit retenir notre attention, mais aussi le bilan très négatif de son expérience monastique. Beaucoup plus qu'un échec cuisant d'apprivoisement de son Éros, son séjour au couvent est perçu comme un terrible emprisonnement et un tourment égal à celui infligé par la passion amoureuse, sinon pire :

Après le départ de la visiteuse vénitienne, sa cellule était paradoxalement devenue pour elle un cachot étouffant. Il lui semblait que les quatre murs s'étaient resserrés, rapprochés et fondus en un seul, que le plafond était descendu, s'était écroulé et avait rencontré le sol et qu'il ne lui apportait plus aucune protection. Son lit s'était transformé en un ardent gril de fer, à l'image de celui sur lequel Saint-Laurent fut rôti vivant ; le chevet n'offrait aucun repos à sa tête, mais la brûlait de toutes parts, enflammant et enfiévrant ses joues; il ne procurait plus de sommeil, mais engendrait des rêves, des rêves constants, étranges et délirants ${ }^{17}$.

On retiendra la pénible impression de resserrement et d'étouffement ainsi que la sensation de torture et de martyre par le feu qui crée un analogon avec la brûlure de l'Éros. La comparaison avec Saint-Laurent qui périt sur le gril ne préfigure-t-elle pas d'ailleurs l'embrasement final de l'héroïne "érotoleptique » à bord du navire de son amant? On relèvera également la discrète supercherie du narrateur qui présente la transformation de la cellule monacale en geôle comme le résultat de la visite de Kaekilia, censée avoir ravivé le souvenir de Sanudo et la passion mal éteinte d'Augusta. Cependant, un autre passage permet de constater que l'établissement religieux a d'emblée été appréhendé par l'héroïne comme un espace rétréci, asphyxiant et 
anxiogène et, bien pire, vécu comme un Enfer brûlant dans lequel la rêverie amoureuse, quoique source de culpabilité, constitue un baume rafraîchissant :

La malheureuse nonne conçut aussitôt des espoirs coupables et plongea dans sa rêverie habituelle, celle à laquelle elle s'abandonnait obstinément tous les jours, s'y jetant pour ainsi dire la tête la première. C'était son seul plaisir et en même temps le plus grand tourment de son âme, comme une station au seuil de l'Enfer où elle s'arrêtait momentanément afin de se remémorer une dernière fois la saveur $d u$ fruit voluptueux de la connaissance, dont il lui semblait sentir encore le jus couler dans sa gorge ; c'était une oasis enchanteresse au milieu de l'infini désert étouffant de l'Éternité ${ }^{18}$.

19 Ce qui promettait d'être un «koĩ

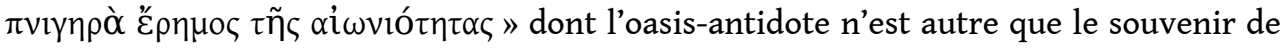
la connaissance du plaisir sexuel. L'inversion opérée par le texte est scandaleuse : l'Éternité est assimilée à la perdition et à la mort alors que le péché originel et la chute représentent le Salut ${ }^{19}$.

Il est vrai que ce "scandale" appartient à l'héroïne: c'est Augusta qui juge subjectivement la réalité du monastère comme infernale; le narrateur se charge simplement, semble-t-il, de décrire les sentiments blasphématoires de son personnage transgressif. Cependant, à regarder le roman de plus près, l'on constate que les autres voix du récit (celles du narrateur, des personnages secondaires, des situations qui «parlent » et qui signifient), le sujet plurivocal du texte ou, si l'on préfère, la logique corrélationnelle du texte (le rapport dialogique des signes linguistiques dans l'espace textuel, l'interrelation et l'interactivité entre les multiples voix) "partagent » le ressenti d'Augusta et « cautionnent » pleinement son point de vue.

21 Lorsque l'on entend par exemple l'extrait du psaume adressé par David au Seigneur «Dieu, c'est toi mon Dieu, je te cherche, mon âme a soif de toi, après toi languit ma chair, terre aride, altérée, sans $e^{20 u^{20}}$ ", intercalé " accidentellement » dans la conversation de Sanudo et Filikiti sur Augusta, l'on ne peut oublier que cette dernière se sentait dans le milieu claustral comme "au milieu de l'infini désert étouffant de l'Éternité ${ }^{21}$ » et se désaltérait au souvenir de ses étreintes charnelles avec le comte vénitien, ce qui suggère, selon la précieuse remarque de Guy Saunier, une identification luciférienne de Sanudo à Dieu $^{22}$, qui n'est certainement pas l'œuvre d'Augusta, mais bien celle du narrateur en charge du récit. Le blasphème ne doit plus être attribué à l'héroïne incandescente, au personnage participant à la diégèse, mais à l'instance narrative extradiégétique-hétérodiégétique, organisatrice du verbe discursif et médiatrice des énoncés romanesques, voire à l'instance auctoriale, si l'on prend en compte l'abondance des citations bibliques et l'importance particulière de David dans le corpus papadiamantien ${ }^{23}$.

Il ne saurait nous échapper par ailleurs que la cellule de l'héroïne dans le monastère de Saint-Jean l'évangéliste, à Patmos, est décrite comme une excavation sommairement aménagée, un "antre ${ }^{24}$ ", qui, comme l'indique René Bouchet, participe du monde souterrain ${ }^{25}$, ou, si l'on préfère, du monde "d'en bas »; le spectre de l'Hadès plane déjà dans la première présentation "objective " des lieux. La perception du couvent par l'héroïne comme un "tombeau provisoire", dans la suite du récit, ne fera que confirmer la complicité entre cette dernière et le narrateur qui, le premier, avait esquissé, « fantasmé » une cellule pénitentielle ensevelie.

C'est alors qu'un bouleversement absolu secoua l'âme de cette femme. Cela ressemblait à une émigration de la raison, à une mort éphémère. Elle décida de se 
considérer comme provisoirement décédée, attendant le trépas définitif. Et puisque, malgré cette révolution intérieure, elle était toujours en vie et dans la même réalité, et qu'elle ne supportait plus l'atmosphère confinée du monastère dans lequel elle s'était réfugiée comme dans un tombeau provisoire, incapable d'y demeurer plus longtemps, elle pensa - en fait, elle ne pensa pas, elle obéit à son instinct - se réfugier... où cela? Précisément au point de départ de tous ses malheurs ${ }^{26}$.

\section{Saint-Kosmas à Naxos, est dépeint ni plus ni moins que comme une prison ${ }^{27}$. René} Bouchet résume :

L'enceinte est fermée par un pont-levis et le caractère de séquestration de cette nouvelle retraite se lit a contrario dans le récit de l'évasion d'Augusta; en particulier dans son angoisse de ne pas parvenir à tromper la vigilance de la Supérieure Filikiti et dans sa précipitation de s'emparer des clés ${ }^{28}$.

evenir moine, c'est donc être frappé de la malédiction la plus épouvantable, c'est subir le sort le plus affreux. C'est aller s'ensevelir tout seul; c'est choisir la mort au détriment de la vie ; bref, c'est commettre un suicide. Un suicide lent, car il ne s'agit pas de trancher brutalement le fil de son existence, mais au contraire de s'attarder sur le moment du trépas, de prolonger indéfiniment l'instant fatidique et angoissant du dernier souffle. Peut-on imaginer pire masochisme? Le discours « décaviardé » de cette 
«folle shakespearienne» de Kaekilia laisse penser que dans la décision et dans la démarche effective d'endosser l'habit monastique sommeille une érotisation de la pulsion de mort et une jouissance perverse.

À cette condamnation plurivocale de la vie monacale viennent enfin s'ajouter les commentaires naïfs d'un batelier, qui, ayant vu Augusta s'enfuir du monastère SaintJean de Naxos, considère que celle-ci a échappé aux griffes des moines, qu'il considère comme des rapaces de la pire espèce :

N'est-ce pas un péché que tous ces beaux fruits finissent dans la bouche de ces sales moines! Ils accaparent toutes les offrandes, les aumônes, les bons vins et même les belles femmes! Quels vilains présages ont dû marquer le destin de ce pays pour qu'il subisse ces corbeaux noirs qui le rendent encore plus noir ${ }^{32}$ !

L'extrait se prête de surcroît à une extrapolation intertextuelle: les « $\mu \alpha \tilde{v} \rho \alpha$

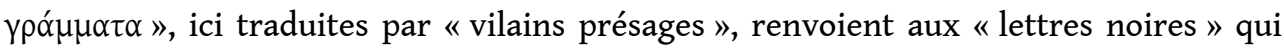
prédisent l'avenir de la Belle-Mère asservie ['H $\left.\Theta \eta \tau \varepsilon i ́ \alpha ~ \tau \tilde{\eta}_{\varsigma} \pi \varepsilon v \theta \varepsilon \rho \tilde{\alpha} \varsigma\right]$, dans laquelle Charmolina, simple mortelle incapable de les lire, commet la folie de se marier pour le

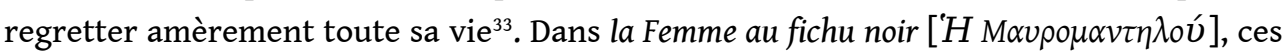
messages incompréhensibles, pourtant lisibles pour le chaste Yannios, sont

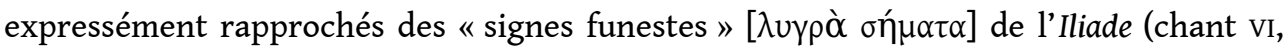
150-205) et donc du destin mortel écrit sur les tablettes que Bellérophon, âme pure qui avait repoussé les avances d'une femme lascive, transporte avec lui à son insu ${ }^{34}$. Nous pouvons donc discerner dans l'univers papadiamantien un triptyque morose réuni autour de la référence aux présages tragiques que l'on porte sur le crâne: le destin lugubre de la mort (la Femme au fichu noir), le destin atroce de l'hymen (la Belle-Mère asservie) et le destin néfaste de la vie monacale (les Marchands des Nations).

\section{L'inauthenticité de la faune monacale}

On soulignera le caractère illusoire de la piété monastique dépeinte dans le roman. En dehors de l'héroïne principale refugiée au couvent pour soigner son Éros maladif, qui ne s'intéresse nullement au salut de son âme, qui désire éperdument son amant-Dieu et se moque royalement de la religion, toute une série de personnages et de situations du récit consolident l'impression que la vie claustrale est dépourvue de toute transcendance divine et de toute essence métaphysique. On insistera sur la suprématie des pulsions érotiques qui marginalisent tout autre souci et toute autre préoccupation. Comment ignorer par exemple que le monastère Saint-Kosmas de Naxos abrite aussi deux autres maîtresses de Sanoutos, Fortuna et Pronia, et que cet homme lubrique et orgiaque détient une clé qui lui permet d'entrer à son gré dans ce lieu sacré et supposé réservé aux âmes assoiffées de Dieu ${ }^{35}$ ? C'est en ce même endroit que le comte vénitien rencontre d'ailleurs nuitamment l'higoumène, avec qui il entretient des liens privilégiés troublants, pour lui parler de son amante Augusta! Filikititi, de son côté, figure hautement ambivalente, est une femme qui respire la volupté et le sexe (« Kaì

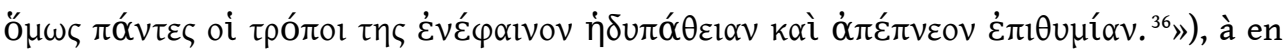
croire le narrateur hétérodiégétique, qui se plaît à la contempler, admirant son teint laiteux ainsi que sa jeunesse inaltérable ${ }^{37}$. La supérieure du monastère devient de cette façon le double d'Augusta, blanche comme le lait, chaude comme la braise et parfaitement préservée des outrages du temps ${ }^{38}$ ! 
s'arrêtera plus particulièrement sur le frère Nehemias, moine de Saint-Jean-leThéologien, à Patmos, qui offre ses services à Augusta-Agapè. Il raconte à Mouchras, qui se présente à lui en tant que parent lointain de l'héroïne, une vision surnaturelle qui se veut récit d'un affranchissement du "démon de la luxure », mais qui souligne en réalité la puissance de l'Éros sous la mince barrière de l'habit monastique et la fragilité du vœu de chasteté. En même temps, cette vision scénarise un effroyable fantasme de castration qui barre l'accès vers la femme et qui se transfigure par une formidable pirouette, classiquement «papadiamantienne" en une victoire morale et un étouffement « héroïque » de la pulsion :

Il lui sembla qu'il se trouvait dans le narthex de l'église de Saint-Jean l'évangéliste et qu'il était en train de prier en silence avec recueillement. Soudain, sur le mur d'en face, sur lequel l'Hadès était dépeint sous la forme d'une bête affamée dévorant les âmes pécheresses qui se jetaient dans sa gueule béante, il vit la face de la bête se transformer tout à coup, prendre un visage humain, celui d'une ravissante femme luxurieuse, dont les traits rappelaient étonnamment ceux de la sœur Agapè. Sa gueule, auparavant hideuse et bestiale devint une belle bouche de jeune femme, elle cessa de dévorer et d'avaler les âmes pécheresses; en revanche, elle vomissait, elle vomissait sans cesse. Elle ne vomissait pas des êtres humains, mais (et c'est cela qui surprit Nehemias, qui comprit avec frayeur que les pécheurs se métamorphosaient dans l'Hadès en démons) elle vomissait des démons. Des démons difformes, cornus et pourvus de queues, qui ressemblaient à divers animaux. Cette vision contribua très efficacement à délivrer le frère Nehemias de l'emprise du démon de la luxure (un démon bien puissant et dangereux, coiffé d'une telle pléthore de cornes qu'il arrive à en frapper presque toute l'humanité) : depuis, et cela - l'effet de la vision -, était plus paradoxal encore que la vision elle-même, il ne voyait plus la sœur Agapè ravissante et séduisante, mais telle une vieille femme laide et toute ridée. En somme, par le biais de ce miracle surnaturel, il se libéra une fois pour toutes des visites envahissantes du fourbe et vicieux démon. Et il fut désormais capable d'aider par pitié cette pauvre pécheresse qui avait perdu la voie de la vérité pour consoler son éphémère enveloppe charnelle, sans plus courir les dangers qui assiègent constamment ce corps fait d'argile, ni redouter les pièges que Satan tend en travers des pieds des anachorètes de ce vain monde ${ }^{39}$.

Notons d'abord que la prière, la tentative de contact avec le religieux, tourne au cauchemar érotique, ce qui suggère l'échec de la communication avec Dieu. Nous discernons ensuite une double transformation: l'Hadès zoomorphe devient la séduisante Agapè et la gueule hideuse qui dévore (les âmes pécheresses) se change en bouche voluptueuse qui excrète (des démons phalliques). En ce qui concerne la première image, elle indique vraisemblablement l'origine démoniaque et infernale de l'Éros ou peut-être encore la mort morale que la tentation sexuelle implique pour un moine. Quant à la seconde, si l'on adopte l'assimilation freudienne de la bouche (par une transposition vers le haut à cause du refoulement) au vagin ${ }^{40}$ - confirmée d'ailleurs par un nombre considérable de mythes ${ }^{41}-$, l'on aboutit inévitablement au fantasme de la vagina dentata, autrement dit de la femme castratrice et mutilatrice qui risque

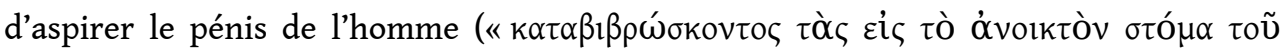

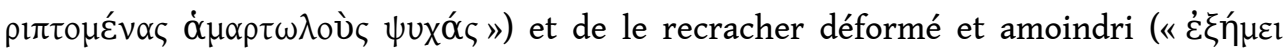

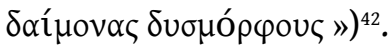

On retiendra surtout que cette vision qui frappe à jamais l'attirance sexuelle d'épouvante et d'abomination est sublimée en miracle et rationalisée en chaste " guérison ». On songe inévitablement à la vision surnaturelle de Yoryis dans Éros-Héros $\left[" E \rho \omega \varsigma-\eta^{\prime} \rho \omega \varsigma\right]$, qui court-circuite «miraculeusement» l'Éros du personnage. Comme la 
vérité intertextuelle de l'œuvre papadiamantienne nous le montre ${ }^{43}$, c'est précisément cette " castration " qui conduit l'homme au monastère et non l'inverse. Il est intrigant enfin de constater que ce moine devenu imperméable aux sollicitations libidinales «impures» s'appelle Nehemias, prénom rarissime et impossible à dissocier du personnage éponyme de l'Ancien Testament dont une vieille tradition extra-biblique parvenue jusqu'à nous a fait un eunuque ${ }^{44}$, donc un homme littéralement émasculé, stérile et impuissant.

En dehors de la lascivité qui éclipse la piété, d'autres éléments du roman mettent sérieusement en doute l'authenticité de l'univers claustral. On mentionnera en premier lieu la remise en question de l'utilité de la confession par l'abbé Ammoun. Lorsque cet homme chaste - au nom vraisemblablement inspiré par le saint de l'Église orthodoxe, qui, contraint au mariage par ses parents, persuada son épouse de ne pas consommer le mariage et de renoncer à la vie mondaine, afin de préserver leur virginité et d'embrasser ensemble un idéal ascétique ${ }^{45}$ - se trouve confronté à la sincérité déconcertante d'Augusta-Agapè, qui avoue qu'elle ne s'est jamais repentie de son amour adultère pour Sanudo, il se rend compte que lui n'a jamais été véritablement franc envers son père spirituel et que nul finalement, hormis cette femme singulière, ne l'est avec son confesseur, ce qui le conduit à conclure à l'inanité dudit sacrement ${ }^{46}$. Il n'est pas anodin d'ailleurs que la confession "authentique ${ }^{47}$ " d'Augusta soit

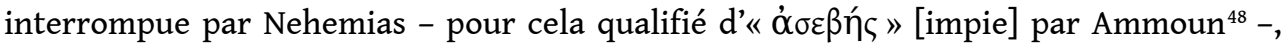
venu prévenir l'héroïne que deux visiteurs la cherchent, ce qui confirme que, dans ce monastère, les choses du monde priment sur la spiritualité et le divin.

Dans cette mascarade de religiosité, on rangera aussi l'indévotion de la mère Zinovia, qui se dispense de messe sous le prétexte que la Supérieure Filikiti l'a autorisée à célébrer une cérémonie privée dans sa cellule monacale ${ }^{49}$. Si son nom fait référence à la sainte orthodoxe qui fut décapitée avec son frère Zinovios pour avoir clamé haut et fort sa profonde foi chrétienne, l'ironie est à peine voilée. Quant à Filikiti, censée être un modèle de dévouement spirituel et de piété en tant qu'higoumène, elle couronne en triomphe cette parodie du monde monastique d'abord par son passé sulfureux - on apprend notamment qu'elle est entrée dans les ordres parce qu'il ne lui restait plus d'autre solution après avoir échoué dans tous les domaines ${ }^{50}-$, et ensuite parce qu'elle prône des idées hérétiques, par exemple lorsqu'elle explique à Augusta que l'attrait de l'inconnu constituait à son sens la motivation principale des sacrifices des martyrs chrétiens et que l'amour du mystérieux est le mobile fondamental de la foi ${ }^{51}$ ! Le comble de la dérision de la vie monacale est atteint avec Mouchras, l'époux cocufié et déshonoré d'Augusta - autre déçu et déchu de l'amour -, qui se fait moine à la fin du

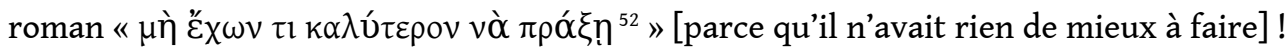
La boucle est bouclée : entrer au monastère, c'est embrasser la fausseté et, en même temps, signer un contrat avec le ridicule.

En définitive, la condamnation du monde monastique est unanime dans ce roman: toutes les voix et toutes les voies signalent, indiquent, soulignent, crient, fustigent et convergent vers l'inauthenticité de ce microcosme censé constituer un havre d'apaisement, un asile assurant la paix intérieure et le contact profond et véridique avec le divin. Précisons qu'il s'agit d'un dénigrement certes polyphonique (au sens étymologique de plusieurs phonès, multiples voix qui s'expriment), mais pas dialogique (au sens bakhtinien d'une pluralité de consciences et d'univers idéologiques, d'une diversité de discours qui se confrontent et se contredisent ${ }^{53}$ ). Nous parlerions 
volontiers d'un décrit plurivocal, mais univoque, univalent, unilogique (ou monologique, pour employer un terme plus usité en théorie de la littérature), voire théologique (puisque dicté par un point de vue absolu coïncidant avec le tout d'un Dieu). La religion discursive des Marchands des Nations est, à l'instar du monde chrétien dépeint dans toute l'œuvre du "Saint des Lettres grecques", indubitablement monothéiste.

\section{En guise de conclusion}

Papadiamantis exprimera son hostilité envers la vie monastique tout au long de son œuvre, mais aussi son attirance, comme on peut le déduire de la récurrence de héros

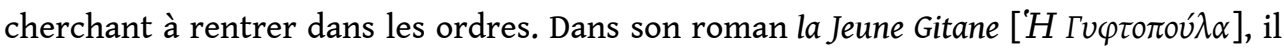
reprendra l'esquisse du monastère en institution irréligieuse et espace carcéral tout en le peuplant de névrosés et de sociopathes dépeints de manière bouffonne. Dans les

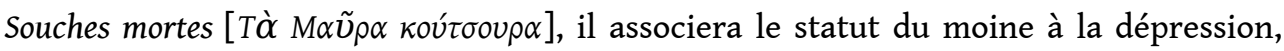

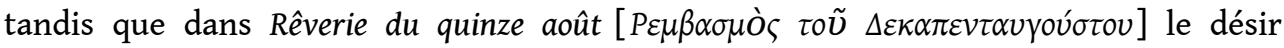
anachorétique sera subrepticement annexé au masochisme. Dans les Rivages roses [T⿳亠㐅⿵

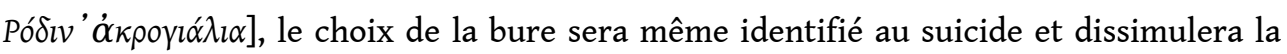
peur viscérale du féminin. Bien plus qu'un succédané de la mort, dans la Belle-Mère asservie ['H $\left.\Theta \eta \tau \varepsilon i ́ \alpha \tau \tilde{\eta}_{\zeta} \pi \varepsilon v \theta \varepsilon \rho \tilde{\alpha} \varsigma\right]$ le couvent constituera une solution pour échapper au cercle infernal de l'hymen et de la reproduction, alors que dans la Meurtrière ['H Фóvi $\sigma \sigma \alpha]$, le point d'orgue, l'état religieux sera assimilé à une stérilité exaltante et à une prévention des meurtres de petites filles susceptibles de devenir un jour fécondes!

$\mathrm{Au}$ travers des contradictions que l'idéal monastique recouvre émerge la figure

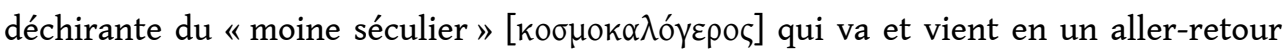
infernal entre le siècle et la règle et fait écran au désir et à l'angoisse de la proximité

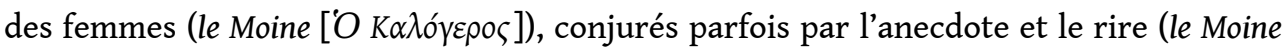

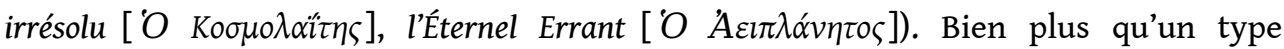
littéraire, le kosmokalogeros constitue le deuxième titre attribué à Papadiamantis, après celui du "Saint des Lettres grecques", qui fait référence au goût de l'auteur pour l'ascétisme, le retrait et la solitude, mais peut suggérer par ailleurs sa passion pour l'activité érémitique et sublimatoire de la littérature...

\section{BIBLIOGRAPHIE}

Aretaki Marina (2001), Aspects de la poétique des romans d'A. Papadiamantis (1879-1884) : Genèse et Fin d'un univers romanesque [Microforme], Lille : ANRT.

Bouchet René, (2001), Le Nostalgique : l'Imaginaire de l'espace dans l'œuvre d'Alexandre Papadiamantis, Paris : Presses de l'Univ. de Paris-Sorbonne (coll. Anaskelas).

Freud Sigmund, (1967) l'Interprétation des rêves, trad. de l'allemand par I. Meyerson, nouv. éd. augm. et rév. par Denise Berger, Paris : PUF. 


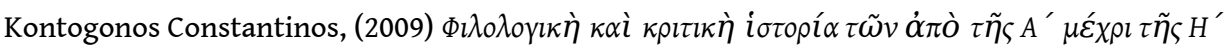

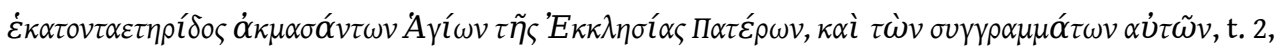

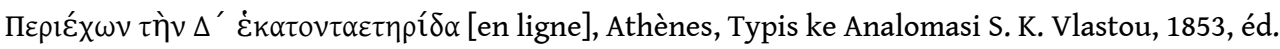
électronique le 15 juin 2009, p. 178.

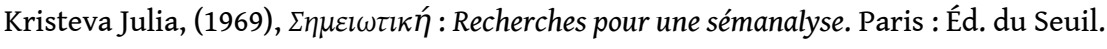

Lederer Wolfgang, (1980) la Peur des femmes ou Gynophobia, Paris : Payot.

Nygren Anders, (2009) Érôs et Agapé (1930), trad. fr. par Pierre Jundt, nouv. éd. Paris : Les Éd. du Cerf.

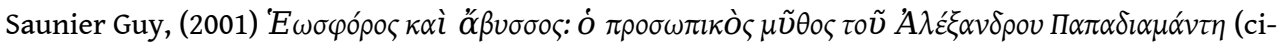
après Eosphoros), Athènes: Agra.

Todorov, Tzvetan, (1981) Mikhail Bakhtine, le principe dialogique, Paris : Seuil.

Yamauchi, Edwin, (2006) »Was Nehemiah the Cupbearer a Eunuch?«, Zeitschrift für die Alttestamentliche Wissenschaft, 1980, vol. 92, $\mathrm{n}^{\circ} 1$ [bibliogr. C2], p. 132-142. Pour une étude exhaustive des eunuques dans la Bible, cf. F. P. Retief, J. F. G. Cilliers et S. P. J. K.

Riekert, "Eunuchs in the Bible«, Acta Theologica [en ligne], Supplementum 7, 2006, vol. 26, $n^{\circ} 2$, p. 247-258.

\section{NOTES}

1. Cf. notre thèse « le Désir érotique dans l'œuvre d'Alexandre Papadiamantis » sous la direction d'Henri TONNET, soutenue à l'Université Paris-Sorbonne en janvier 2012, disponible sur : <http:// www.e-sorbonne.fr/theses/desir-erotique-loeuvre-dalexandre-papadiamantis>.

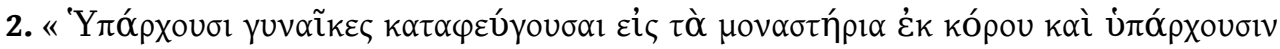

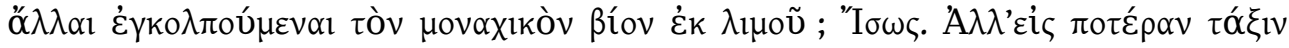

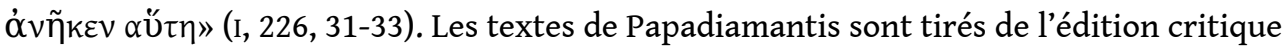
établie par N. D. TRIANTAFYLLOPOULOS, Athènes, Domos, 1981-1992 (six vol. ). Chaque citation est suivie de la mention du volume en chiffres romains, de la page en chiffres arabes, et de la ligne en chiffres arabes après la référence de la page. La traduction française des extraits cités a été effectuée par nos soins.

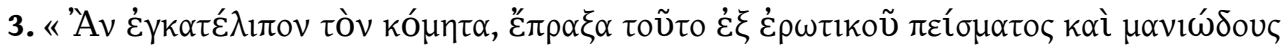

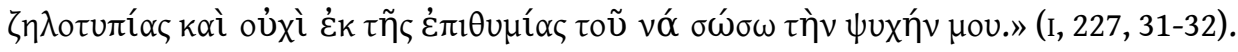

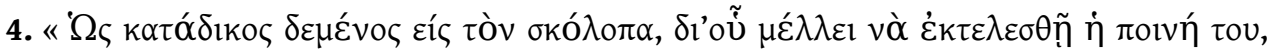

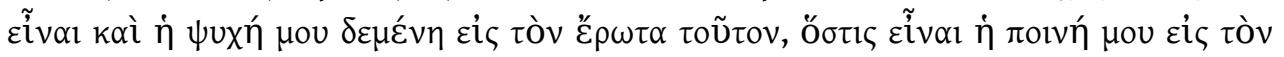

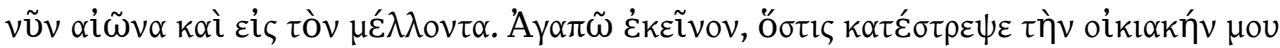

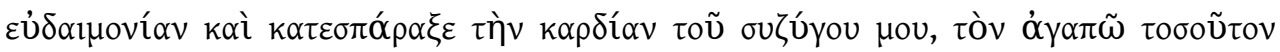

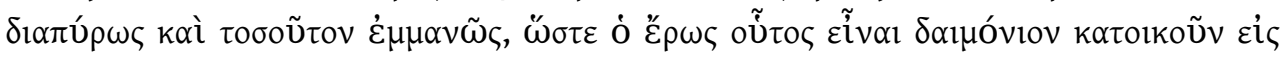

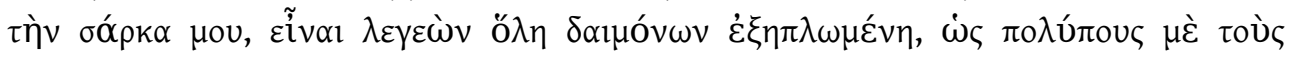

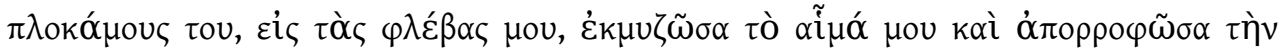
$\pi v o \eta ́ v ~ \mu o v . »(\mathrm{I}, 228,27-35)$.

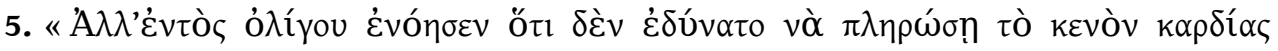

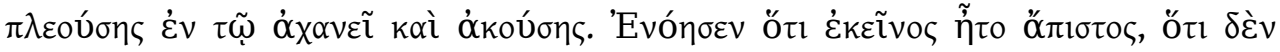

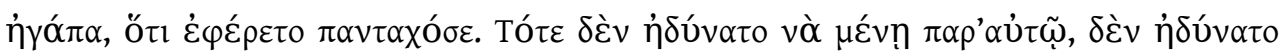

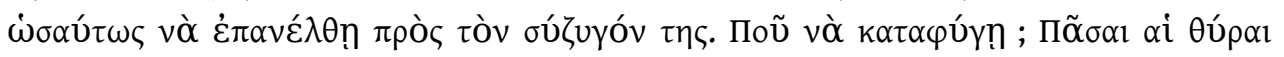




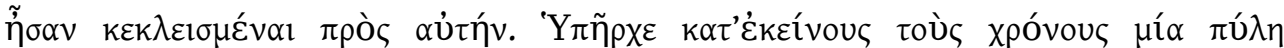

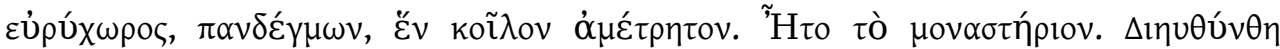

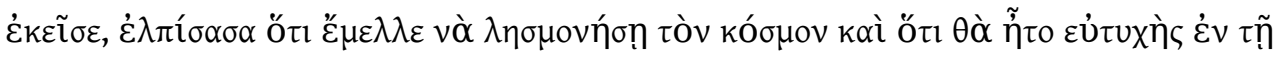

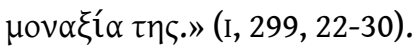

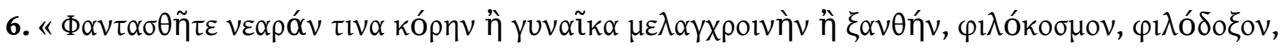

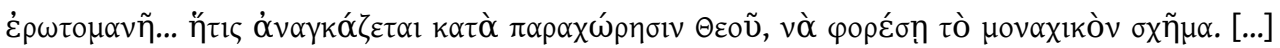

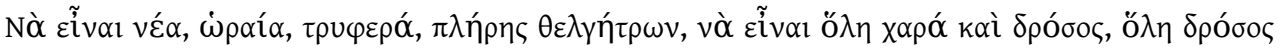

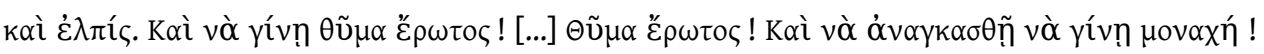

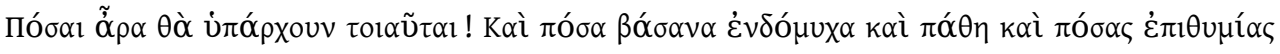

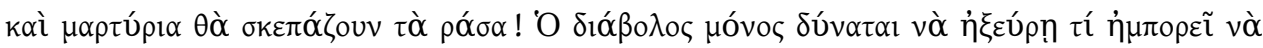
ن்

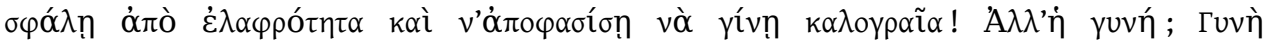

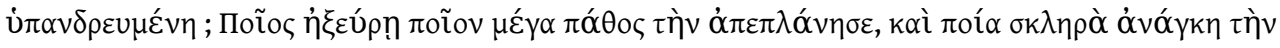

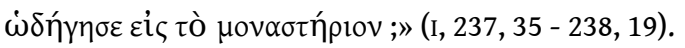

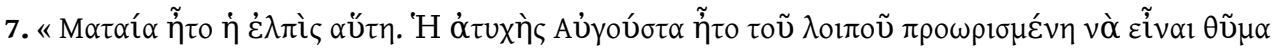

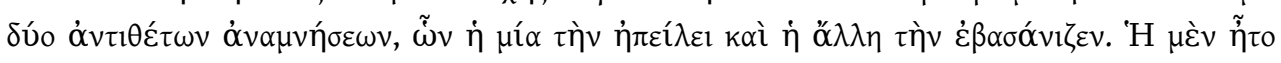

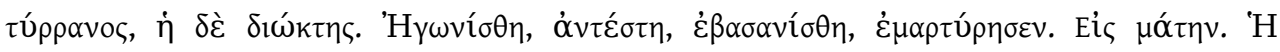

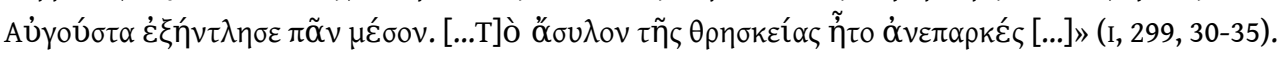

8. L'audace des propos d'Augusta constitue peut-être l'une des raisons pour lesquelles le roman a

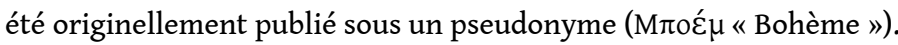

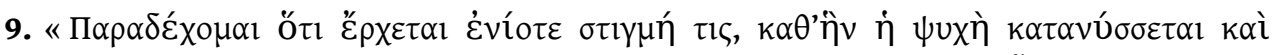

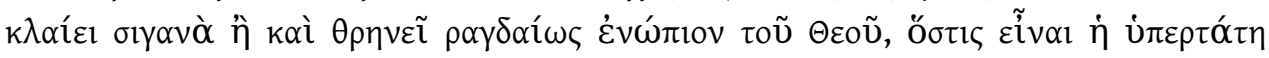

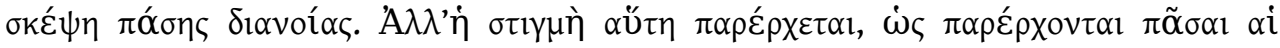

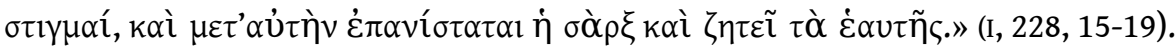

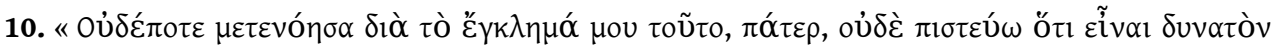

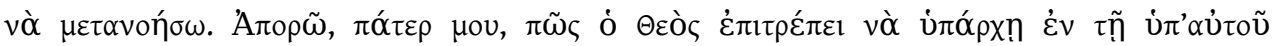

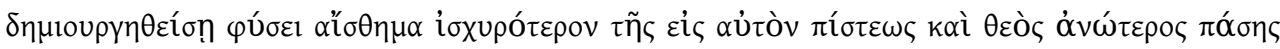

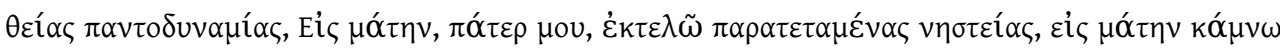

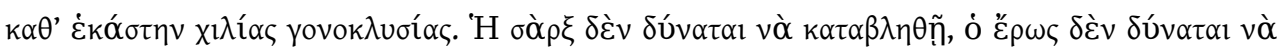
ن்

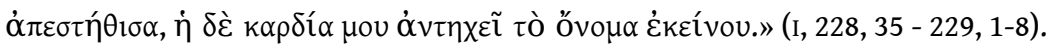

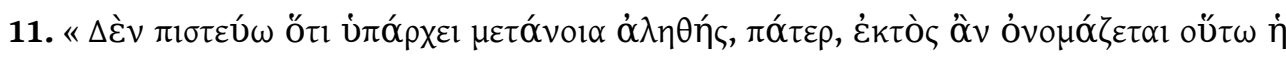

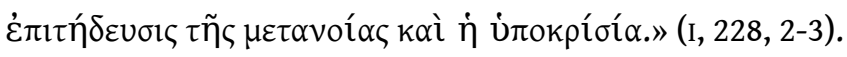

12. Nous soulignons la préposition "pour» afin de bien mettre en exergue le fait que les «proches» et «Dieu» doivent être entendus comme des objets et non pas comme des sujets; dans ce dernier cas, « de » serait de mise. Notre remarque est redevable à l'analyse fort subtile de la grammaire de Dieu opérée par le grand théologien suédois A. Nygren, qui décrit comment le va-et-vient du génitif objectif et du génitif subjectif se décline dans les modalités de l'amour : 1 .

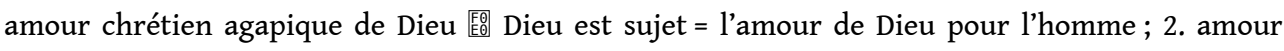

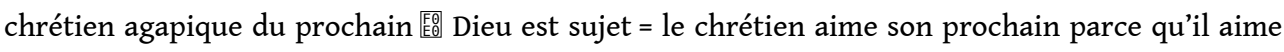
Dieu et il aime Dieu parce que Dieu l'aime (voilà pourquoi Dieu est sujet dans cette formule avec « de ») ; 3. amour de désir « céleste » ( Éros sous sa forme sublimée) pour Dieu 䦪 Dieu est objet; 4. amour ( = Éros) de soi 爁 soi est objet. Pour le développement détaillé de ce quartette, cf. A. NYGREN, Érôs et Agapé (1930), t. 1, trad. fr. par Pierre JUNDT, nouv. éd. Paris, Les Éd. du Cerf, 2009, p. 236-245.

13. I, 227, 7-8. 


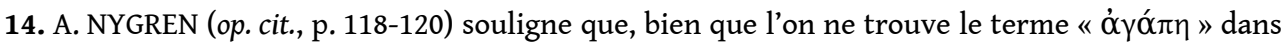
les Synoptiques qu'à titre exceptionnel et bien que l'on ne puisse pas prouver qu'il s'agit véritablement d'une création linguistique du christianisme, c'est à lui qu'il doit sa consécration en tant que désignation caractéristique de l'amour chrétien. Le théologien suédois indique en outre que, quoiqu'il soit possible que l'on ait usé de ce mot au sein de l'Église primitive avant

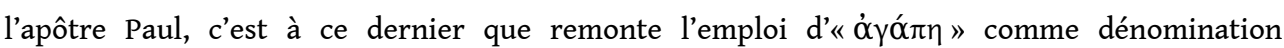
spécifique de l'amour chrétien. Nygren précise que Paul ne s'est pas contenté d'utiliser ce terme, mais qu'il a en même temps défini ce qu'il désignait, l'a introduit dans ses écrits, ainsi transmis aux générations nouvelles et que, grâce à lui, Agapè s'est imposée comme mobile fondamental du Christianisme.

15. IV, 244, 7-8. Pour Stamatis - ou, selon N. D. TRIANTAFYLLOPOULOS (IV, 723, gloss.), pour

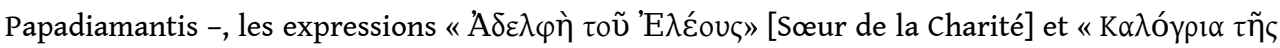

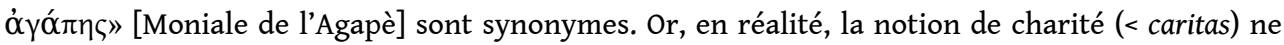
coïncide pas avec celle d'Agapè. A. Nygren consacre la plus grande partie du troisième volume de son œuvre Érôs et Agapè à l'éclaircissement de la notion de charité qui syncrétise des éléments du concept de l'Éros platonicien et néoplatonicien et de celui de l'Agapè chrétienne. Dans l'avantpropos du premier volume de l'édition de 2009, Lucrèce Luciani-Zidane résume : « La caritas (bien loin d'être la traduction automatique de l'agapè comme cela est habituellement présenté, j'y insiste) est cette synthèse géniale mais dont Nygren nous démasque le paradoxe, celui d'un amour naturel, c'est-à-dire humain et entièrement formé par le désir d'éros qui se perfectionne, se purifie avant de pouvoir s'achever dans le don gracieux de l'agapè par le dénominateur de l'égoïsme naturel. » (L. LUCIANI-ZIDANE, Avant-propos (à la nouv. éd.), in A. NYGREN, op. cit., p. XII.)

16. Signalant le contraste entre l'Éros et l'Agapè dans sa thèse Aspects de la poétique des romans d'A. Papadiamantis (1879-1884): Genèse et Fin d'un univers romanesque [Microforme], Lille, ANRT, 2001, t. 2, p.380, Marina ARETAKI soutient que le nom qu'Augusta s'approprie au monastère suggère un souhait de l'héroïne de changer et de trouver un autre type d'amour ; la chercheuse ne fait néanmoins aucune allusion à l'échec du personnage d'imposer sa volonté sur son désir ni à l'ironie retentissante que cet échec revêt.

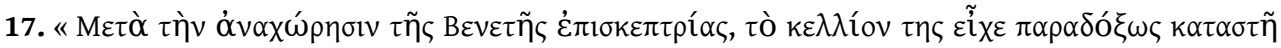

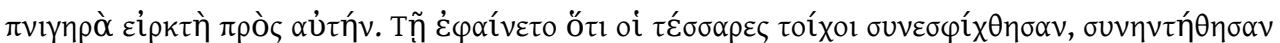

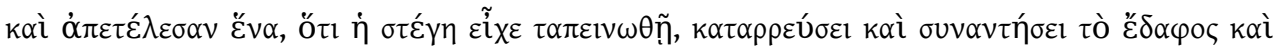

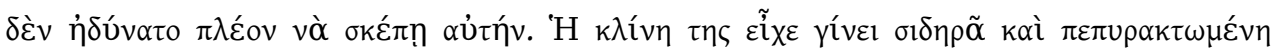

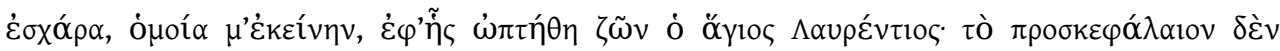

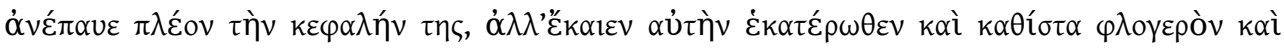

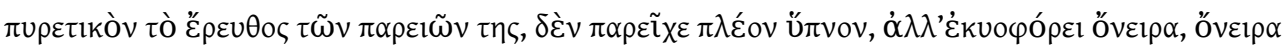

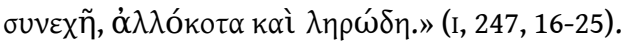

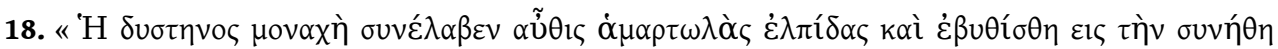

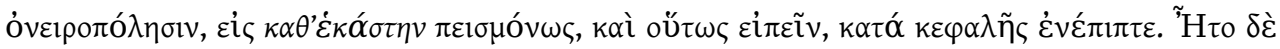

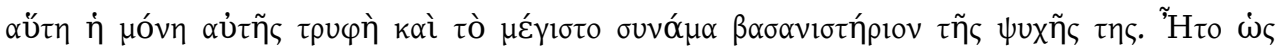

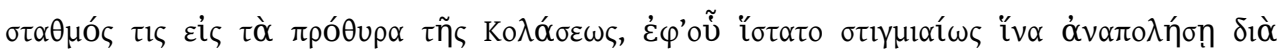

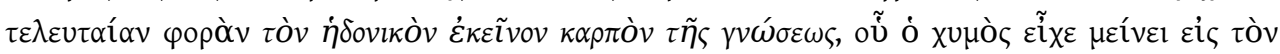

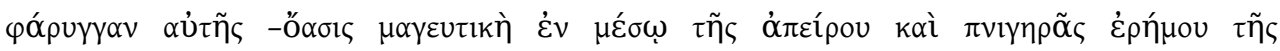

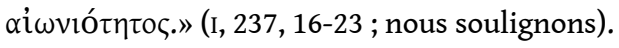

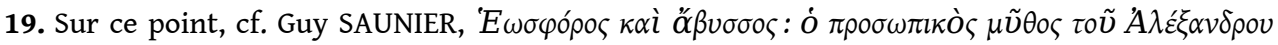
$\Pi \alpha \pi \alpha \delta i \alpha \mu \alpha ́ v \tau \eta$ (ci-après Eosphoros), Athènes, Agra, 2001, p. 184-185. Sur l'essence libidinale du péché originel dans l'imaginaire papadiamantien (à l'inverse de sa perception dans la tradition orthodoxe qui insiste sur l'infraction au commandement divin et sur le désir d'égaler Dieu sans 
référence à la sexualité), cf. notre thèse «le Désir érotique dans l'œuvre d'Alexandre Papadiamantis », op. cit., p. 619-622.

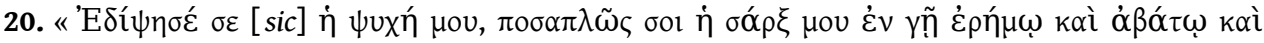

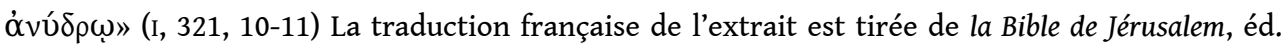
intégralement rev., corr. et revêtue de l'Imprimatur (Rome, le 30 sept.), Paris, Les Éd. du Cerf, 1999 [ $1^{\text {re }}$ éd. : $1955 ; 2^{\mathrm{e}}$ éd. rev. : 1973].

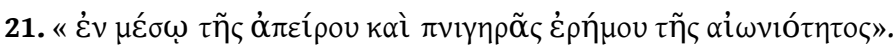

22. G. SAUNIER, Eosphoros, p. 186-187.

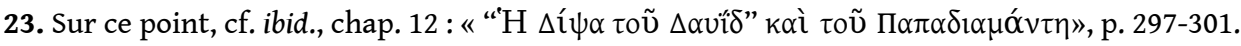

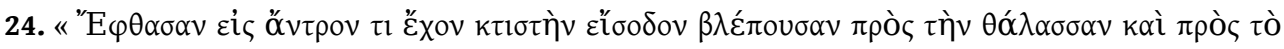

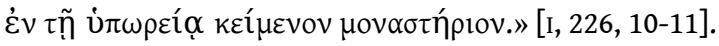

«Ils sont arrivés dans un antre possédant une entrée maçonnée donnant sur la mer et sur le monastère au pied de la montagne. »

25. René BOUCHET, le Nostalgique: l'Imaginaire de l'espace dans l'œuvre d'Alexandre Papadiamantis, Paris, Presses de l'Univ. de Paris-Sorbonne (coll. Anaskelas), 2001, p. 53.

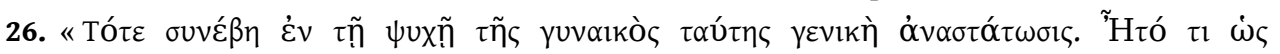

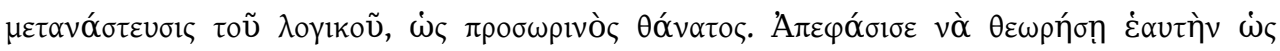

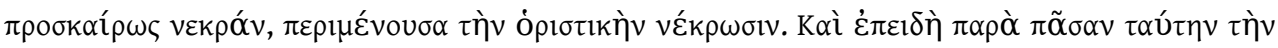

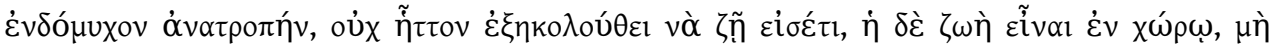

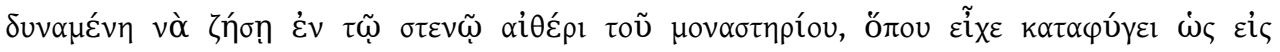

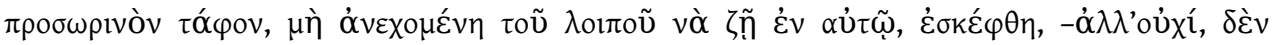

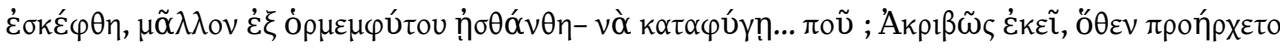
$\pi \tilde{\alpha} \sigma \alpha \dot{\eta} \delta$ v $\tau u x i ́ \alpha \tau \eta \varsigma »$. I, 300, 1-9.

27. I, 286-290.

28. R. BOUCHET, op. cit., p. 53.

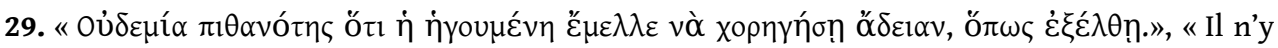
avait aucune chance que l'higoumène donnât à Augusta la permission de sortir. » (I, 289, 24-25).

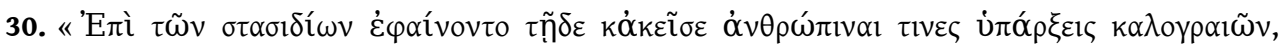

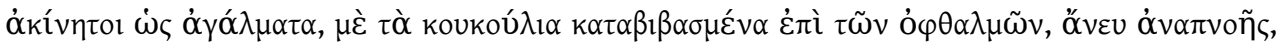

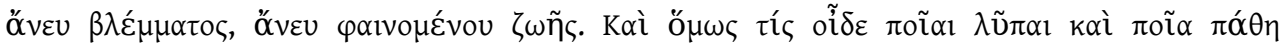

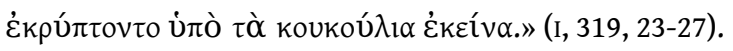

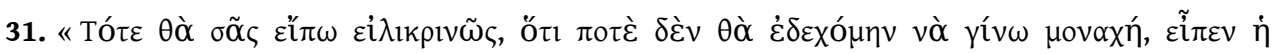

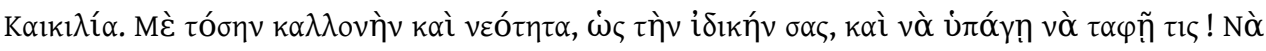

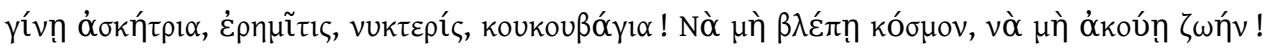

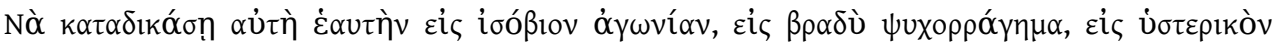

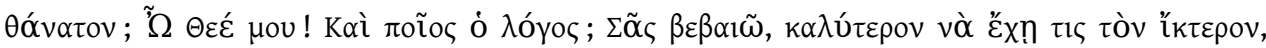

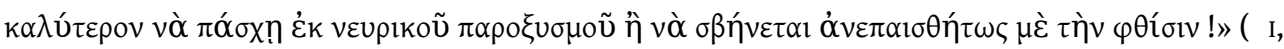
234, 1-8).

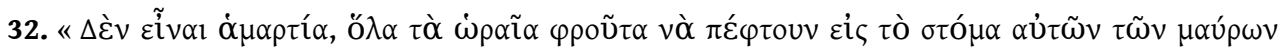

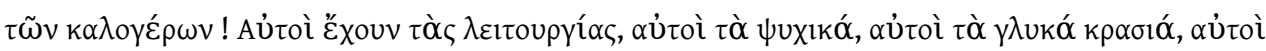

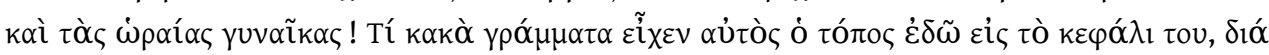

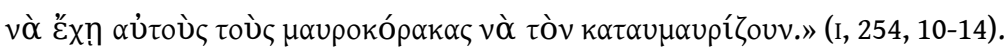

33. III, $408,30-409,2$.

34. II, 155, 14-21.

35. I, 318, 13-22.

36. I, 285, 25-26.

37. I, 285, 14-22.

38. Les deux femmes sont par ailleurs stériles. 


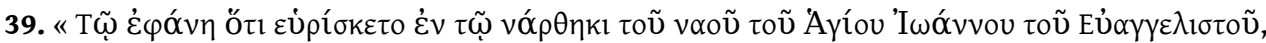

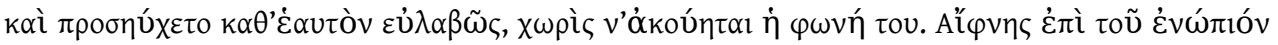

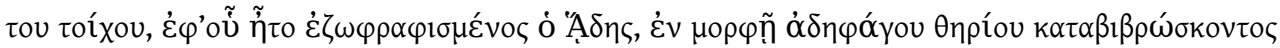

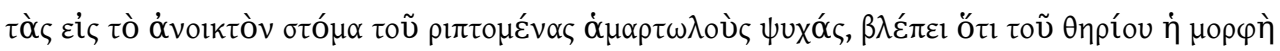

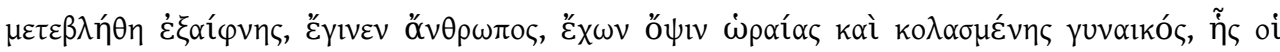

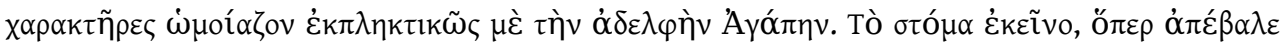

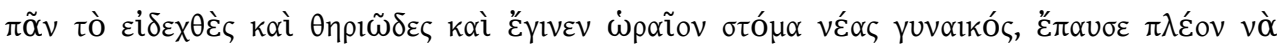

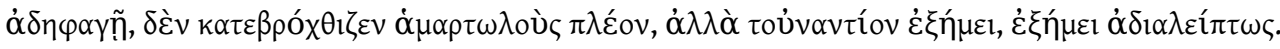

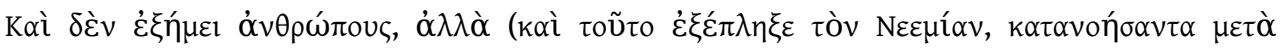

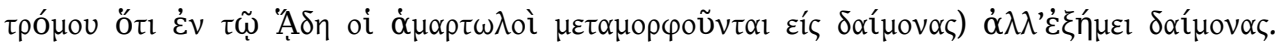

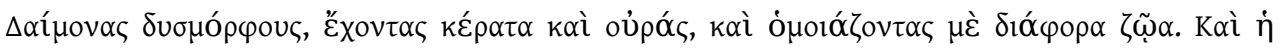

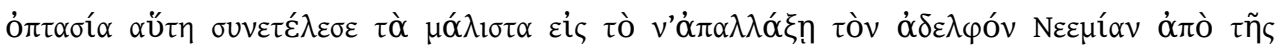

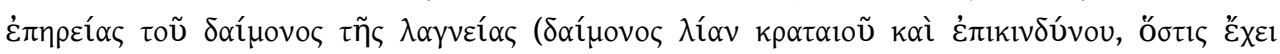

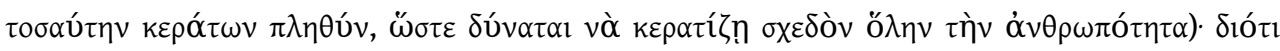

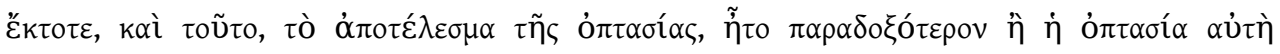

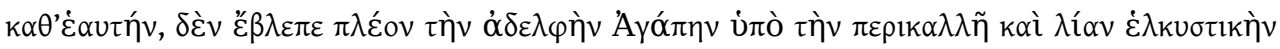

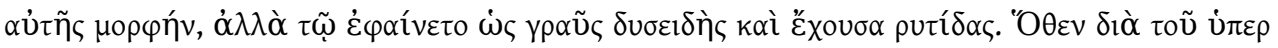

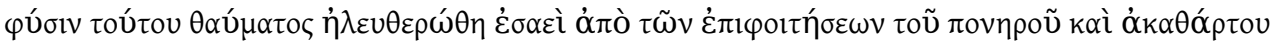

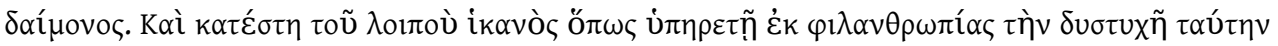

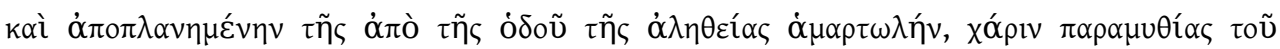

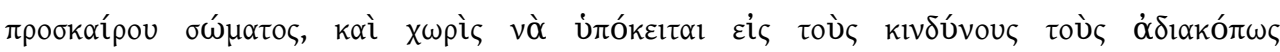

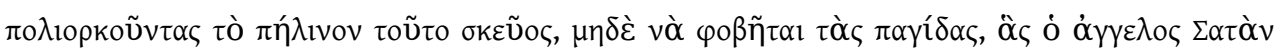

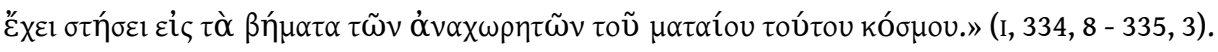

40. Cf. Sigmund FREUD, l'Interprétation des rêves, trad. de l'allemand par I. MEYERSON, nouv. éd. augm. et rév. par Denise BERGER, Paris, PUF, 1967, p. 308. Cf. aussi, sur l'équivalence translinguistique entre lèvres buccales et vulvaires, I. FONAGY, « Les bases pulsionnelles de la phonation, » in La Vive Voix: Essais de psychophonétique, Paris, Payot, 1991 [1 $1^{\mathrm{re}}$ éd. : Payot, 1983], p. 85-88.

41. Cf. Encyclopédie des symboles, Paris : Librairie générale française, 1996, s. v. bouche.

42. Sur la vagina dentata (mythe folklorique rencontré dans plusieurs cultures et concept psychanalytique désignant l'angoisse inconsciente de la castration de l'homme par les organes génitaux féminins), cf. Wolfgang LEDERER, la Peur des femmes ou Gynophobia, Paris, Payot, 1980, chap. VI: «Dents assassines», p. 44-51 et chap. XxIII : «L'envie du pénis et la peur de la castration », p. 197-203. Sur le fantasme de castration dans la vision de Nehemias, cf. également l'avis de G. SAUNIER, Eosphoros, p. 333.

43. Cf. la nouvelle de Papadiamantis le Moine.

44. Dans la Bible, aucun témoignage explicite n'indique que Nehemias (hébreu : רְִֶ? Ne'hemya, "YHWH a consolé ») était eunuque: le mot hébreu saris utilisé en règle générale dans l'Ancien Testament pour désigner les hommes émasculés, qui correspond au mot grec « $\varepsilon \dot{v} v o \tilde{x} x o \zeta$ » utilisé dans le Nouveau Testament, n'est jamais appliqué au personnage. L'on déduit facilement du livre éponyme qui lui est consacré que Nehemias était célibataire (il n'avait ni parents, ni épouse, ni descendance) et l'on apprend qu'il fut échanson du roi perse Artaxerxès II (Néhémie $1: 11$ ), fonction de haut rang souvent exercée dans les cours achéménides par des hommes châtrés, ce qui explique la

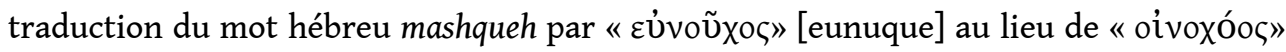
[porte-tasse] dans deux manuscrits de la Septante (Codex Vaticanus et Codex Sinaiticus), erreur certes scribale liée à la similitude des deux mots en grec, mais il paraît néanmoins difficile d'écarter l'éventualité d'un lapsus lectoral. L'idée de l'assimilation 
du personnage à un eunuque - idée bien ancrée dans le judaïsme hellénisé, qui puise son origine, de l'avis des spécialistes, dans un fragment de Ctésias (médecin grec au service d'Artaxerxès II, historien de la Perse et de l'Inde) qui atteste que les échansons royaux étaient à son époque des eunuques - est accréditée par le fait que Nehemias servait aussi bien en présence de la reine que du roi et qu'en outre, on tente de lui faire passer la nuit dans une section du Temple dont il sait qu'elle lui est interdite ; or, selon la Loi juive, aucun homme dont les testicules ont été écrasés ou dont le pénis a été coupé ne peut être admis à l'assemblée de YHWH, c'est-à-dire dans certaines parties du Temple. Dans la tradition exégétique, le premier à reconnaître explicitement Nehemias en tant qu'eunuque fut le théologien égyptien Origène qui, prenant à la lettre l'enseignement du Christ sur les gens qui se sont « eux-mêmes rendus tels [Eủvoúxol] à cause du Royaume des Cieux» (Matthieu 19:12), se castra lui-même. Le débat sur la vérité historique de l'émasculation de Nehemias se poursuit aujourd'hui encore parmi les biblistes. Pour un récapitulatif et un examen critique de cette argumentation, cf. Edwin M. YAMAUCHI, "Was Nehemiah the Cupbearer a Eunuch ?», Zeitschrift für die Alttestamentliche Wissenschaft, 1980, vol. 92, n 1 [biblgr. C2], p. 132-142. Pour une étude exhaustive des eunuques dans la Bible, cf. F.P. RETIEF, J. F. G. CILLIERS et S.P. J. K. RIEKERT, "Eunuchs in the Bible", Acta Theologica [en ligne], Supplementum 7, 2006, vol. 26, $\mathrm{n}^{\circ} 2$, p. 247-258, disponible sur: <http://ajol.info/index.php/actat/article/ viewFile/52578/41183> (consulté le 18 jan. 2010).

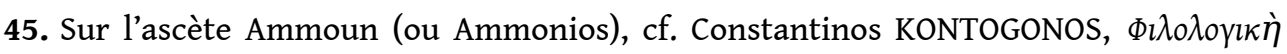

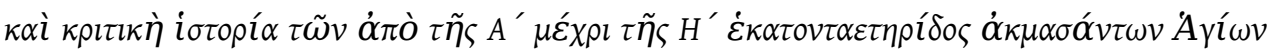

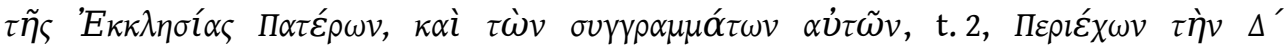
$\dot{\varepsilon} \kappa \alpha \tau o v \tau \alpha \varepsilon \tau \eta \rho i ́ \delta \alpha$ [en ligne], Athènes, Typis ke Analomasi S. K. Vlastou, 1853, éd. électronique le $15 \mathrm{ju}$ [in ?] 2009, p. 178, disponible sur :

<http://pc3.lib.uoi.gr:8080/jspui/handle/123456789/HASH01a5ad9335a42362645e2f29> (consulté le 21 jan. 2011).

46. I, 229, 9 - 230, 2.

47. La confession d'Augusta est authentique du point de vue de l'honnêteté et de la franchise dans l'aveu de la faute, mais inauthentique par l'absence de repentir.

48. I, 231, 27.

49. I, 288, 7-8.

50. I, 162 .

51. I, 286, 11-16.

52. I, 342, 29 .

53. Cf. Tzvetan TODOROF, Mikhail Bakhtine, le principe dialogique, chap. 5 : «Intertextualité",

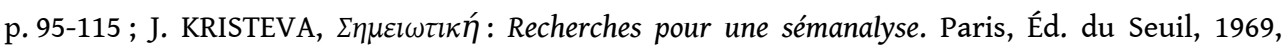
chap. 4 : Le mot, le dialogue et le roman, p. 82-112; ead., Préf. : "Une poétique ruinée», in Mikhaïl BAKHTINE, la Poétique de Dostoïevski, [Paris], Éd. du Seuil, 1998, p. 5-29. 


\section{RÉSUMÉS}

L'article se propose d'explorer certaines représentations littéraires de la vie monastique dans l'œuvre de l'écrivain «national » de la Grèce moderne Alexandre Papadiamantis. Nous situant aux antipodes de la critique orthodoxe imposant une vision théologique univoque de son univers artistique, notre contribution, qui se centre sur le roman matriciel les Marchands des Nations [Oi

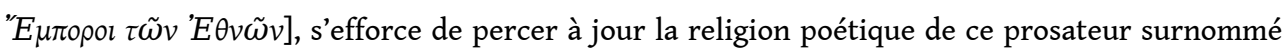
dans son pays natal «le Saint des Lettres grecques». Ainsi sous le vernis d'un récit historique empreint de religiosité émerge un foisonnement de fantasmes, de désirs et de perversions qui confèrent à l'écriture papadiamantienne toute sa richesse et toute son intemporalité.

The present contribution proposes to explore some literary depictions of monastic life in the work of Modern Greece's national writer Alexandros Papadiamantis. Contrary to the orthodox critics, who have imposed a univocal theological approach of his artistic universe, and focusing on his novel The Merchants of Nations [Oi " $E \mu \pi 0 \rho 01 \tau \tilde{\omega} v$ ' $E \theta v \tilde{\omega} v$ ], which holds the germs of his main ideas, we try to reveal the poetic religion of this fascinating writer, dubbed in his home country "the Saint of Greek literature". Thus, under the cover of a historical narrative, a world of fantasies, desires and perversions arises, that endows its writing with a wealth of depth and a timeless quality.

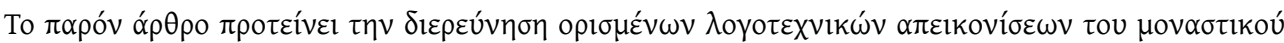

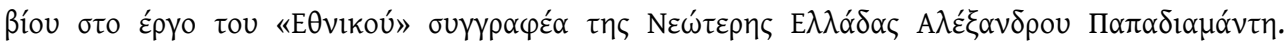

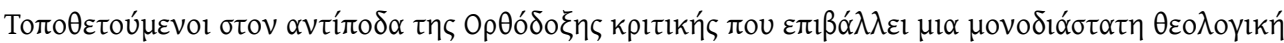

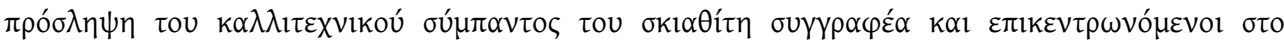

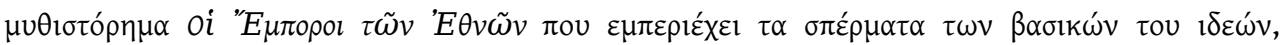

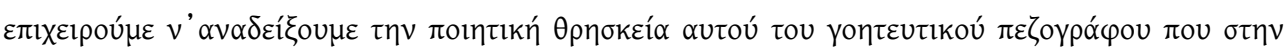

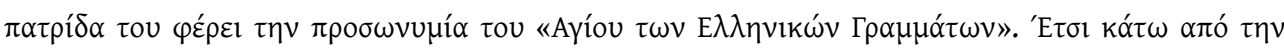

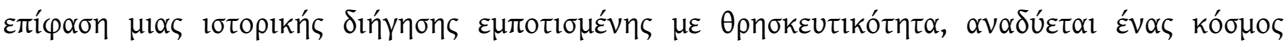

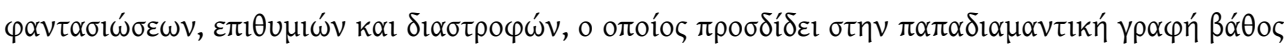

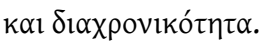

\section{INDEX}

Index géographique : Grèce

Mots-clés : Papadiamantis Alexandre (1851-1911), Papadiamantis Alexandre (1851-1911), vie monastique

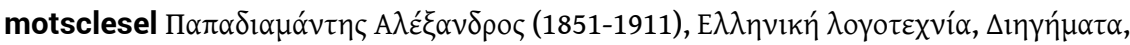

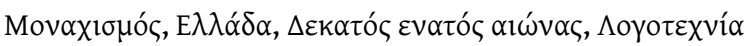

motsclestr Papadiamantis Alexander (1851-1911), Yunan edebiyatı, Kısa hikayeler, Manastır hayatı, Yunanistan, On dokuzuncu yüzyıl, Edebiyat

motsclesmk ПАПАДИАМАНТИС АЛЕКСАНДАР (1851-1911), ГРЧКАТА ЛИТЕРАТУРА, РАСКАЗИ, МОНАШКИОТ ЖИВОТ, ГРЦИЈА, ДЕВЕТНАЕСЕТТИОТ, ВЕК, ЛИТЕРАТУРА

Keywords : Papadiamantis Alexander (1851-1911), Greek literature, Short stories Monastic life, Greece, Nineteenth century, Literature

Thèmes : Littérature, Littérature/religion

Index chronologique : dix-neuvième siècle 
AUTEUR

NICOLAS EVZONAS

Docteur es lettres

Paris IV Sorbonne 